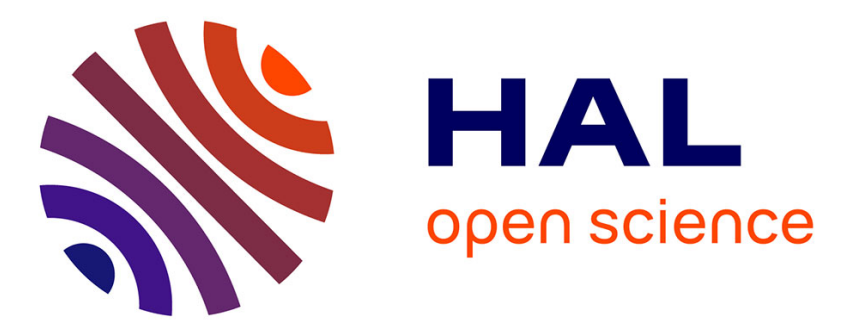

\title{
Emotional overeating is common and negatively associated with alcohol use in normal-weight female university students
}

Aymery Constant, Yentl Gautier, Nicolas Coquery, Ronan Thibault, Romain Moirand, David Val-Laillet

\section{To cite this version:}

Aymery Constant, Yentl Gautier, Nicolas Coquery, Ronan Thibault, Romain Moirand, et al.. Emotional overeating is common and negatively associated with alcohol use in normal-weight female university students. Appetite, 2018, 129, pp.186-191. 10.1016/j.appet.2018.07.012 . hal-01856971

\section{HAL Id: hal-01856971 \\ https://hal.science/hal-01856971}

Submitted on 13 Feb 2020

HAL is a multi-disciplinary open access archive for the deposit and dissemination of scientific research documents, whether they are published or not. The documents may come from teaching and research institutions in France or abroad, or from public or private research centers.
L'archive ouverte pluridisciplinaire HAL, est destinée au dépôt et à la diffusion de documents scientifiques de niveau recherche, publiés ou non, émanant des établissements d'enseignement et de recherche français ou étrangers, des laboratoires publics ou privés. 
Emotional overeating is common and negatively associated with alcohol use in normal-weight female university students

Aymery Constant (1,2), Yentl Gautier (1), Nicolas Coquery (1), Ronan Thibault (1,3), Romain Moirand $(1,4)$, and David Val-Laillet (1)

1. INRA, INSERM, Univ Rennes, CHU Rennes, Nutrition Metabolisms and Cancer, NuMeCan, Rennes, France

2. EHESP, School of Public Health, Rennes, France

3. Unité de Nutrition, CHU Rennes, Rennes, France

4. Unité d'Addictologie, CHU Rennes, Rennes, France

The first two authors contributed equally to this work.

Corresponding Author: D. Val-Laillet, INRA 1341 NuMeCan, 16 Le Clos, 35590 St Gilles, France.david.val-laillet@inra.fr

Funding and Acknowledgments: This project was funded by the INRA Priority Action of the AlimH Division (Nutrition, Chemical Food Safety and Consumer Behaviour) and coordinated by David Val-Laillet. The PhD grant of Yentl Gautier was provided by INRA and Région Bretagne, France. We acknowledge the staff of the SIMPSS (Service Interuniversitaire de Médecine Préventive et de Promotion de la Santé) of Rennes, and 
especially Dr. Valérie Casin, who contributed to the recruitment of the volunteers. We also thank Noémie Réthoré and Orlane Petitgas who participated in data preparation.

Authors' contribution: YG, NC, RM, RT and DVL contributed to study design, recruitment, and data gathering; YG and DVL supervised the administrative and legal processes; AC analysed the data and wrote the first version of the paper; all co-authors contributed to interpreting the results and revising the paper.

Keywords: emotion; eating disorders; food questionnaires; coping 


\begin{abstract}
Introduction

Eating in response to specific emotional cues was hitherto investigated in relation to weight gain, eating disorders, and psychiatric and addictive disorders. Given the difficulties in treating established obesity, preventive interventions towards normal-weight subjects could be more appropriate and cost effective. In order to design such interventions, it is important to characterize emotional overeating in normal-weight subjects, especially young women.
\end{abstract}

Methods

Female university students aged 18-24 years with healthy Body Mass Index (comprised between 18.5 and 24.9) were asked to complete questionnaires while attending a medical consultation. Emotional Eating frequency in the last 28 days was assessed together with data on habitual physical activity, drinking patterns, substance abuse, suspected eating disorders and cognitive/behavioural components of eating. Sociodemographic data and tobacco use were also collected.

Results

Half of participants reported intermittent Emotional Overeating in the last 28 days, mostly during one to five days in the last 28 days, in response to Anxiety (51.3\%), Loneliness (45.1\%), Sadness (44.8\%), and Happiness (43.6\%), and to a lesser extent in response to Tiredness (27.4\%) and Anger (14.6\%). In multivariate analysis, Distress-Induced Overeating (DIO) correlated positively with inability to resist emotional cues, disordered eating symptoms, and loss of control over food intake. It correlated negatively with moderate and excessive drinking.

Conclusion

A large proportion of normal-weight female students used intermittent overeating episodes as a time-limited response to emotional states, especially anxiety. DIO was negatively correlated with alcohol use, which suggests two distinct and somewhat exclusive ways of coping with negative emotions. It was higher in the minority of students with disordered eating symptoms and loss of control over food intake, highlighting the need for a systematic screening in all female students entering college. 


\section{Introduction}

High school and university students have to cope with many issues such as academic pressure, autonomy from parents, financial difficulties, and social competition or isolation, among others (D. R. Adams, Meyers, \& Beidas, 2016; Boujut \& Bruchon-Schweitzer, 2009). Many of them engage in physical and social activities to relieve stress and get social support (Decamps, Boujut, \& Brisset, 2012). But when they fail to adapt adequately, they may display maladaptive coping behaviours (Deasy, Coughlan, Pironom, Jourdan, \& McNamara, 2015). A study conducted in France showed that one out of five students drank alcohol more than 10 times a month, and that $3.7 \%$ consumed cannabis more than 10 times per month. Regarding high-risk alcohol consumption, $32.5 \%$ of the study population misused alcohol, with $18.7 \%$ of students experiencing frequent bouts of drunkenness (Tavolacci et al., 2013). While men are largely overrepresented among students with alcohol and substance abuse (Verger, Guagliardo, Gilbert, Rouillon, \& Kovess-Masfety, 2010), women seem to be more vulnerable to disordered eating (Tavolacci et al., 2015), e.g. chronic restrained eating, binge eating disorder commonly known by compulsive overeating, with associated loss of control.

Research also suggests a gender difference in stress-related eating, with women choosing more palatable food (Bennett, Greene, \& Schwartz-Barcott, 2013; Wansink, Cheney, \& Chan, 2003) and being more prone to turn to food for psychological comfort rather than physiological need as regards to men (Jaaskelainen et al., 2015; Kandiah, Yake, Jones, \& Meyer, 2006; Oliver \& Wardle, 1999). In the U.S., weight gain in female college students was negatively associated with being stress-free, eating vegetables, and consuming less highcholesterol foods, and positively associated with alcohol consumption (T. Adams \& Rini, 2007). Another study conducted in three European countries found that perceived stress was associated with more frequent consumption of sweet/fat foods and less frequent consumption of fruits/vegetables in female students, but not in men (Mikolajczyk, El Ansari, \& Maxwell, 
2009). Eating in response to specific emotional cues was hitherto investigated in relation to weight gain (Koenders \& van Strien, 2011; Masheb \& Grilo, 2006), eating disorders (De Young, Zander, \& Anderson, 2014; Pinaquy, Chabrol, Simon, Louvet, \& Barbe, 2003), and psychiatric and addictive disorders (Brunault et al., 2017; Van Strien, Schippers, \& Cox, 1995).

It is of importance to note that overeating, and especially emotional overeating in normalweight young people could further lead to increase in weight and subsequent obesity. Given the difficulties in treating established obesity, preventive interventions towards normal-weight subjects could be more appropriate and cost effective. In order to design such interventions, it is important to characterize emotional overeating in normal-weight subjects, especially young women. Specific objectives were 1) to estimate the frequency of overeating in response to emotions in normal-weight female university students, 2) to determine its factor structure, and 3) to investigate its association with maladaptive coping behaviours, eating patterns and eating disorders suspicion. 


\section{Materials \& Methods}

Participants and procedure

The INRA data protection agent approved the declaration of conformity of this questionnaire study, which was used for the selection of volunteers to be included in a laboratory neurocognitive study conducted at the Rennes University Hospital and approved by an independent national research ethics committee (Comité de Protection des Personnes "Ile de France II", project $\mathrm{N}^{\circ}$ 2017-03-03; NID-RCB/EUDRACT 2017-A00133-50; National Clinical Trial number: NCT03076489). The data used and provided in this paper or as supplemental data, were completely anonymized, with no mean to infer the volunteers' identity. Female university students aged 18-24 years with healthy Body Mass Index (between 18.50 and 24.99) who either responded to a call for volunteers via students' mailing-lists or attended a visit in a clinic devoted to university students (SIMPSS, Université de Rennes, Brittany, France) between January 2017 and January 2018 were eligible. Initial instructions also specified that the final neurocognitive study would not include low French language skills, left-handed subjects, pregnant or lactating women, as well as daily smokers, which might have limited the inclusion of such profiles in our initial questionnaire study. Participants attending a medical visit for psychiatric or addiction problems were also excluded. After free and informed consent, participants completed questionnaires including sociodemographic data: age (in years), weight (in $\mathrm{kg}$ ), height (in $\mathrm{cm}$ ), tobacco use (never, occasional, regular), and several other psychological and behavioural variables as described below. Two subsidiary questions were added to record a recent and significant weight gain/loss or familial history of obesity. Apart from the Emotional Overeating Questionnaire (EOQ), for which determination of the factor structure was one of our goals, only French validated versions of questionnaires were used in this study. 
Frequency of overeating in response to emotions

The Emotional Overeating Questionnaire (EOQ) is a six-item self-report questionnaire that assesses overeating frequency in response to six emotions, namely anxiety, sadness, loneliness, tiredness, anger, and happiness (Masheb \& Grilo, 2006), previously used in a French study (Brunault et al., 2017). Each item begins with, "Have you eaten an unusually large amount of food given the circumstances in response to feelings of (...)". Each of the six emotions is presented in all capital letters, followed by three more synonyms in parentheses and in lower case. The response set for the six items is a 7-point scale reflecting the frequency of days in which the behaviour occurred in the past 28 days (i.e., $0=$ no days, $1=1-5$ days, $2=$ $6-12$ days, $3=13-15$ days, $4=16-22$ days, $5=23-27$ days, and $6=$ every day).

Habitual Physical activity

The Ricci-Gagnon questionnaire $(\mathrm{RG})$ is a French cultural adaptation of the Baecke Questionnaire (Baecke, Burema, \& Frijters, 1982; Duclos et al., 2015) and includes nine items assessing habitual daily activity. Four items are devoted to everyday activities such as walking, climbing stairs, work and handiwork-related activity; four items assess recreational and sport activities; one item assesses sedentary. Responses are scored on a 5-point scale, and anchors can vary across items (e.g., time spent, or never to at least once a week). Final score ranges from 5 to 40 and indicates a low $(<16)$, intermediate $(18-32)$, or high $(>32)$ level of activity. A subsidiary question was added to detect high-level athletes and exclude them from our study, similarly to subjects with a score $>32$. 


\section{Drinking patterns}

The Alcohol Use Disorders Identification Test (AUDIT) is a ten-question test to determine whether a person may be at risk for alcohol abuse problems (Bohn, Babor, \& Kranzler, 1995). The test was designed to be used internationally, and was validated in a study drawing patients from six countries. There is some evidence that the AUDIT works well in young adults and students (Garcia Carretero, Novalbos Ruiz, Martinez Delgado, \& O'Ferrall Gonzalez, 2016; Kelly, Donovan, Chung, Bukstein, \& Cornelius, 2009). In the validated French version of the AUDIT, a score of 6 or more is considered to indicate excessive consumption in women (Gache et al., 2005). Accordingly, participants with AUDIT score $\geq 6$ were categorized as "excessive drinker", while those with scores ranging between 1 and 5 were categorized as "moderate drinker". Participants with null score were categorized as “abstainers".

Substance abuse

The CRAFFT Screening Test consists of a series of 6 questions developed to screen adolescents for high-risk alcohol and other drug use disorders (Karila et al., 2007; Knight, Sherritt, Shrier, Harris, \& Chang, 2002). It is a short, effective screening tool meant to assess whether a longer conversation about the context of use, frequency, and other risks and consequences of alcohol and other drug use is warranted. The questions are the following. 1) Have you ever ridden in a car driven by someone (including yourself) who was "high" or had been using alcohol or drugs? 2) Do you ever use alcohol or drugs to relax, feel better about yourself, or fit in? 3) Do you ever use alcohol/drugs while you are by yourself, alone? 4) Do you ever forget things you did while using alcohol or drugs? 5) Do your family or friends ever tell you that you should cut down on your drinking or drug use? 6) Have you gotten into 
trouble while you were using alcohol or drugs? A score of 2 positive answers or above indicates a potential drug issue. Diagnostic threshold for regular substance use in the French version of the CRAFFT was fixed at two positive answers with a sensitivity of $90.3 \%$ and a specificity of $77.7 \%$ (Karila et al., 2007)

\section{Disordered eating symptoms}

The SCOFF Questionnaire is a five-question screening tool designed to clarify suspicion that an eating disorder (anorexia/bulimia) might exist (Garcia et al., 2010; Morgan, Reid, \& Lacey, 2000). The questions can be delivered either verbally or in written form. S - Do you make yourself Sick because you feel uncomfortably full? C - Do you worry you have lost Control over how much you eat? $\mathrm{O}$ - Have you recently lost more than One stone $(6.35 \mathrm{~kg})$ in a three-month period? F - Do you believe yourself to be Fat when others say you are too thin? F - Would you say Food dominates your life? Diagnostic threshold was fixed at two positive answers with a sensitivity of $94.6 \%$, a specificity of $94.8 \%$ and an area under the curve of 96.2\%. Positive and negative predictive values for Eating Disorders were 65 and 99\%. Similar figures were obtained separately for Anorexia and Bulimia. An answer of 'yes' to two or more questions warrants a more comprehensive assessment. It must be noted that these symptoms might contribute but are not necessarily associated with eating disorders. In the absence of a clinical diagnosis for anorexia/bulimia in the present study, a score $\geq 2$ was only referred as "disordered eating symptoms". 
Cognitive and behavioural components of eating

The Three-Factor Eating Questionnaire Revised, 18-item (TFEQ-R18) measures cognitive and behavioural components of eating (de Lauzon et al., 2004). It includes three subscales: (1) Cognitive Restraint (conscious restriction of food intake in order to control body weight or to promote weight loss) comprised of six items (e.g., "I consciously hold back at meals in order not to gain weight), (2) Uncontrolled Eating (tendency to eat more than usual due to a loss of control over intake accompanied by subjective feelings of hunger), comprised of nine items (e.g., "When I see a real delicacy, I often get so hungry that I have to eat right away"), and (3) Emotional Eating, (inability to resist emotional cues) comprised of three items (e.g., "When I feel blue, I often overeat"). Internal-consistency reliability coefficients (Cronbach's $\alpha$ ) for each of the 3 scales were above the 0.70 standard and below the 0.90 limit recommended for individual assessment. Responses are scored on a 4-point scale, and anchors can vary across items (e.g., definitely true to definitely false, or never to at least once a week). The raw scale scores are transformed to a $0-100$ scale. Higher scores in the respective scales are indicative of greater cognitive restraint, uncontrolled, or emotional eating (de Lauzon et al., 2004).

\section{Statistical analyses}

Categorical data were expressed as numbers $(\mathrm{N})$ and percentages $(\%)$. Numerical data were expressed as means (M) and standard deviations (SD), and compared with a within-subject Analysis of Variance (ANOVA). An exploratory factor analysis was performed on the Emotional Overeating Questionnaire items using an Unweighted Least-Square factor analysis. This method was found to provide accurate and conservative parameter estimates when using ordinal data (Forero, Maydeu-Olivares, \& Gallardo-Pujol, 2009). Factor analysis was followed by a Promax rotation, a non-orthogonal (oblique) solution in which the factors are 
allowed to be correlated. This item reduction method established which of the 6 items in EOQ belonged to latent domains or conceptual areas and which items should be maintained in factor scores. Since our study outcome was a linear variable (factor score), we used generalized linear regression model to estimate the strength of the association between emotional overeating and each covariate in a multivariate analysis. 


\section{Results}

Descriptive analysis

Survey questionnaires were filled by 377 female university students between January 2017 and January 2018, but 18 (4.8\%) were excluded from further analysis because respondents were categorised as high-level athletes, and 24 were rejected because of missing data. The 335 remaining respondents were aged 20.1 years on average (Table 1), with a normal body weight $($ mean $\mathrm{BMI}=21.0, \mathrm{SD}=1.89)$. Most were classified as moderately active $(68.0 \%)$ despite a physical activity mean score (18.3) that was just above the sedentary cut-off (established at 18). AUDIT scores revealed that $32.5 \%$ of respondents had excessive alcohol consumption, while tobacco use (everyday: 7.2\%; occasionally: $7.8 \%$ ) and substance abuse $(12.2 \%)$ were in minority. Disordered eating symptoms (SCOFF $>2$ ) were assessed in $15.8 \%$ of the study sample. TFEQ-R18 standardized subscales mean scores (ranging from 0 to 100) were 31.0 ( $\mathrm{SD}=19.8)$ for Cognitive Restraint; $37.8(\mathrm{SD}=19.4)$ for Uncontrolled Eating; and $46.5(\mathrm{SD}=29.4)$ for Emotional Eating. A one factor Analysis Of Variance (ANOVA) showed that differences between each score was significant $(p<0.001)$, suggesting that inability to resist emotional cues (EE) outweighed other cognitive components of eating in our study sample.

Emotional Overeating frequency in the last 28 days

Four to five respondents in ten reported Emotional Overeating in response to anxiety $(51.3 \%)$; Loneliness (45.1\%); Sadness (44.8\%); and Happiness (43.6\%), in the last 28 days, mostly during 1- to 5-day episodes (Table 2). Tiredness (27.5\%) and Anger (14.9\%) triggered 
overeating in a minority of respondents (Table 2). Unweighted Least-Square exploratory factor analysis followed by a Promax rotation was performed on the 6 EOQ items. After the first rotation, the "Happiness" item was removed because it loaded relatively low $(<0.40)$ on the 2 factors-solution (Eigen values $>1$ ). A final extraction was performed on the remaining 5 items (Anxiety; Loneliness; Sadness; Anger; and Fatigue), resulting in a one-factor solution explaining $57.7 \%$ of the common variance of the data (Table 3 ). This latent variable was interpreted as "Distress-Induced Overeating" (DIO), and a factor score was computed and used as dependent variable in the multivariate analysis. Frequency of overeating in response to Happiness was used as a single outcome.

Multivariate analysis

In multivariate analysis (Table 4), DIO factor score was positively associated with the inability to resist emotional cues (EE), eating behaviour symptoms, and loss of control over food intake (uncontrolled eating, UE). It was negatively associated with moderate and excessive drinking. No relationship was found between covariates and the frequency of overeating in response to happiness. 


\section{Discussion}

Our results showed that half of normal-weight female students included in our study reported intermittent Emotional Overeating in the last 28 days, mostly during one to five days in the last 28 days, in response to Anxiety (51.3\%), Loneliness (45.1\%), Sadness (44.8\%), and Happiness (43.6\%), and to a lesser extent in response to Tiredness $(27.4 \%)$ and Anger $(14.6 \%)$. Exploratory factor analysis evidenced a 1-factor latent variable reflecting "DistressInduced Overeating" (DIO) including all EOQ items but Happiness. In multivariate analysis, DIO factor score correlated positively with inability to resist emotional cues, disordered eating symptoms, and loss of control over food intake. It correlated negatively with moderate and excessive drinking.

Despite the fact that our study sample included young female students with healthy BMI, 1 in 3 was categorised as sedentary. According to recent studies conducted in France, the prevalence of weight issues and eating disorders in female students ranged between $23.1 \%$ and $32.0 \%$, and between $26.4 \%$ and $32.4 \%$, respectively (Tavolacci et al., 2015; Zakhem et al., 2015). The relatively low prevalence of disordered eating symptoms (15.8\%) in our study sample nevertheless indicates that a sizeable proportion of normal-weight female students warrant comprehensive assessments for eating disorders. When it comes to risk behaviours, excessive drinking (32.5\%) was much more frequent than substance abuse $(12.2 \%)$ or regular smoking (7.2\%), but the incidence of smoking might not be representative in our study because instructions specified that daily smokers would not be included in the final study. Alcohol misuse constitute a recent but increasing problem among young French women (Richard et al., 2015), towering others risk and addictive behaviour in the present study. 
Cognitive and behavioural components of eating were similar in our study sample as regards to the young female sample included in the French TFEQ-18 validation study (de Lauzon et al., 2004). Inability to resist emotional cues outweighs other eating cognitive components of eating during early adulthood, while Cognitive Restraint increases in later years (de Lauzon et al., 2004). Accordingly, half of participants reported overeating in response to anxiety in the last 28 days, and 4 in 10 in response to loneliness, sadness and happiness. This intermittent coping response seemed however under control, as a large majority reported occurrence of emotional eating less than five days in the last month.

Previous studies have underscored the specific role of anxiety and depression on overeating (Bittencourt, Lucena-Santos, Moraes, \& Oliveira Mda, 2012; Peterson, Latendresse, Bartholome, Warren, \& Raymond, 2012; Rosenbaum \& White, 2015). Our factor analysis suggested that others negative emotions - namely sadness, anger, loneliness and tiredness were also involved in a latent variable reflecting a broader "Distress-Induced Overeating". In addition, some positive emotions such as happiness may also influence food intake, in a specific way that warrant further investigations (Bongers, Jansen, Havermans, Roefs, \& Nederkoorn, 2013; Braden, Musher-Eizenman, Watford, \& Emley, 2018).

In multivariate analysis, DIO had the strongest independent association with inability to resist emotional cues (EE), which is probably a typical characteristic of French young women rather than a pathological form of eating behaviour. Yet it was aggravated in the minority of students with disordered eating symptoms, and correlated with loss of control over food intake, highlighting the need for a systematic screening in normal-weight young students. This has been also advocated in recent studies connecting emotional eating and addictive behaviour or weight gain (Bourdier et al., 2018; Sanlier et al., 2017). Conversely, DIO negatively correlated with alcohol use, suggesting that alcohol drinking may replace overeating as a way to cope with negative emotions, especially anxiety (Brook \& Willoughby, 
2016). This hypothesis seems corroborated by preclinical studies in rats showing that intermittent access to high-fat diet attenuates alcohol intake through reducing anxiety-like behaviour (Sirohi, Van Cleef, \& Davis, 2017a, 2017b). Interestingly, this negative relationship was not linear in our study, since factor score correlated moderate drinking more significantly than it correlated excessive drinking. Students' drinking intensity often result from underlying motives and expectations towards alcohol (Kuntsche, Knibbe, Gmel, \& Engels, 2005). While moderate drinking tend to reflect social drinking, i.e. when people drink for social facilitation, improvement of social gathering, or to get in a party mood, excessive drinking is more related to negative emotions avoidance, impulsivity, and academic difficulties (Brook \& Willoughby, 2016; Hamilton, Ansell, Reynolds, Potenza, \& Sinha, 2013; Labouvie \& Bates, 2002; Tembo, Burns, \& Kalembo, 2017). Accordingly, moderate drinkers may have benefited from enjoyments and social interactions to improve well-being (Sandstrom \& Dunn, 2014), while excessive drinkers merely replaced excessive eating with excessive drinking to cope with distress. Interestingly, Benjamin \& Wulfert (2005) suggested that women who either binge eat or abuse alcohol have similar dispositional characteristics and exhibit a high degree of impulsivity ('externalizers') compared to women who admitted both addictive behaviours and were not particularly impulsive but presented a high degree of emotional instability ('internalizers'). Since we did not assess impulsivity, it is not possible to discuss this possible dichotomy between 'externalizers' and 'internalizers' in our subjects with moderate and excessive drinking. Finally, no relationship was found with habitual physical activity or substance abuse in our study, probably because they constitute factors influencing profoundly well-being rather than intermittent responses to stress (Evers, Adriaanse, de Ridder, \& de Witt Huberts, 2013; Kloos, Weller, Chan, \& Weller, 2009; Tyson, Wilson, Crone, Brailsford, \& Laws, 2010). 
This study must be interpreted in light of its limitations. First, inclusion and exclusion criteria limited the extrapolation of results to female students with lower prevalence for addictive disorders and psychiatric disorders. In addition, the exclusion of high level athletes might have selected persons with lower proportion of disordered eating symptoms. Second, the cross-sectional design does not allow determining causal inferences about relationships between Emotional Overeating and others covariates under investigation. Better understanding of the interactions between stress, coping, eating styles, disordered eating symptoms, and emotional overeating among normal-weight students warrants a prospective study and follow-up assessments over the university year or cycle. Second, the EOQ has a single item for assessing each emotion-related eating and was not validated in French. The factor analysis revealed a single item ("Happy Eating") that was not properly investigated in the present study. Finally, data were collected using self-report questionnaires, which makes possible the existence of false negative questionnaire results and excludes the possibility to control for psychiatric disorders. However, the SCOFF questionnaire seemed relevant to detect a minority of vulnerable students.

\section{Conclusions and perspectives}

Overall, a large proportion of normal-weight female students used intermittent overeating episodes as a time-limited response to emotional states, especially anxiety. Distress-Induced Overeating seemed related to behavioural component of eating typical of young women, and was negatively correlated with alcohol use, which suggests two distinct and somewhat exclusive ways of coping for negative emotions. Yet, DIO was higher in the minority of students with disordered eating symptoms, and loss of control over food intake, highlighting the need for a systematic screening in all female students entering college for preventive 
purposes. In terms of perspective, excessive eating and drinking seem to be two different ways to cope with similar emotions. It would be of interest to identify specific food items towards which emotional eating might be targeted, and investigate whether or not alcohol mitigates their consumption in stressful situations. A better understanding of the neurobiological and neurocognitive mechanisms underlying compulsive and emotional eating would also improve prediction, diagnosis, and therapeutic interventions related to disordered eating (Moore, Sabino, Koob, \& Cottone, 2017; Val-Laillet et al., 2015). Interventional studies are also necessary to assess whether a causal relationship exists between DIO and disordered eating symptoms. It is not yet possible to characterize DIO as a cause of eating disorders rather than as a mere associated behavioural trait. 
Table 1: Characteristics of the respondents, categorical variables $(\mathrm{N}=335)$

\begin{tabular}{|c|c|c|}
\hline \multicolumn{2}{|l|}{ Variables } & $\mathrm{N}(\%)$ \\
\hline \multirow[t]{3}{*}{ Tobacco use frequency } & Everyday & $24(7.2)$ \\
\hline & Occasionally & $26(7.8)$ \\
\hline & None & $285(85.1)$ \\
\hline \multirow[t]{2}{*}{ Level of Activity (RG) } & Moderate & $227(68)$ \\
\hline & Sedentary & $108(32)$ \\
\hline \multirow[t]{3}{*}{ Drinking patterns (AUDIT) } & Excessive drinking & $109(32.5)$ \\
\hline & Moderate drinking & $183(54.6)$ \\
\hline & Abstinence & $43(12.8)$ \\
\hline \multirow[t]{2}{*}{ Substance abuse (CRAFTT) } & Yes & $41(12.2)$ \\
\hline & No & $294(87.8)$ \\
\hline \multirow[t]{2}{*}{ Disordered eating symptoms (Scoff) } & Yes & $53(15.8)$ \\
\hline & No & $282(84.8)$ \\
\hline \multirow[t]{3}{*}{ Components of Eating (TFEQ-R18) $\dagger$} & Cognitive restraint & $31.0(19.8)$ \\
\hline & Uncontrolled eating & $37.8(19.4)$ \\
\hline & Emotional eating & $46.5(29.4)$ \\
\hline
\end{tabular}

$\dagger$ : The raw scale scores were transformed to a $0-100$ scale [((raw score - lowest possible raw score $) /$ possible raw score range $\times 100$ ]. Higher scores in the respective scales are indicative of greater cognitive restraint, uncontrolled, or emotional eating. 
Table 2: Emotional Eating days in the last 28 days in response to six emotional states among the study sample $(\mathrm{N}=335)$. Data are expressed as Number and Percentages (\%).

$$
0 \text { day } \quad 1-5 \text { days } \quad 6-12 \text { days } \quad 13-15 \text { days } \quad>16 \text { days }
$$

\begin{tabular}{cccccc} 
Anxiety & $163(48.7)$ & $123(36.7)$ & $25(7.5)$ & $9(2.7)$ & $15(4.5)$ \\
Sadness & $185(55.2)$ & $115(34.3)$ & $21(6.3)$ & $6(1.8)$ & $8(2.4)$ \\
Loneliness & $183(54.9$ & $114(34.0)$ & $22(6.6)$ & $7(2.1)$ & $8(2.4)$ \\
Anger & $284(85.1)$ & $39(11.6)$ & $4(1.2)$ & $2(0.6)$ & $5(1.5)$ \\
Tiredness & $243(72.5)$ & $60(17.9)$ & $14(4.2)$ & $5(1.5)$ & $13(3.9)$ \\
Happiness & $189(56.4)$ & $96(28.7)$ & $29(8.7)$ & $11(3.3)$ & $10(3.0)$ \\
\hline
\end{tabular}


Table 3: EOQ Items and factor loadings for the 2- and the 1-factor solutions

\begin{tabular}{cccc}
\hline & \multicolumn{2}{c}{2 -factor solution $\dagger$} & 1 factor solution $\$$ \\
\cline { 2 - 3 } EOQ Items & Factor 1 & Factor 2 & \\
\hline Anxiety & 0.70 & 0.12 & 0.78 \\
Sadness & 0.87 & -0.50 & 0.78 \\
Loneliness & 0.68 & -0.03 & 0.72 \\
Anger & 0.63 & -0.08 & 0.66 \\
Fatigue & 0.64 & 0.53 & 0.55 \\
Happiness & 0.31 & 0.25 & \\
& & & 2.40 \\
Eigen value & 3.00 & 1.01 & 57.7 \\
\% of variance & 43.7 & 10.2 & 0.81 \\
Cronbach Alpha & & & \\
\hline
\end{tabular}

$\dagger$ : Rotated factor loadings following unweighted least square extraction and oblique (promax) rotation; $\ddagger$ Unrotated factor loadings following unweighted least square extraction, after the "Happiness" item was removed 
Table 4: Factors associated with distress-induced overeating factor score, Generalized Linear Model

\begin{tabular}{|c|c|c|c|c|c|c|}
\hline Variables & & $\mathrm{B}$ & $\begin{array}{l}\text { Standard } \\
\text { Error }\end{array}$ & $95 \% \mathrm{CI}$ & $\begin{array}{l}\text { Wald Chi- } \\
\text { Square }\end{array}$ & $\mathrm{p}$-value \\
\hline Age (in years) & & -0.24 & 0.02 & $-0.07-0.03$ & 0.98 & NS \\
\hline Body Mass Index & & 0.01 & 0.02 & $-0.03-0.06$ & 0.22 & NS \\
\hline \multirow[t]{2}{*}{ Tobacco use frequency } & Everyday & -0.07 & 0.18 & $-0.43-0.29$ & 0.13 & NS \\
\hline & $\begin{array}{r}\text { Occasionally } \\
\text { Never }\end{array}$ & $\begin{array}{c}-0.06 \\
\text { ref }\end{array}$ & 0.17 & $-0.39-0.27$ & 0.14 & NS \\
\hline Level of Activity (RG) & $\begin{array}{l}\text { Moderate } \\
\text { Sedentary }\end{array}$ & $\begin{array}{c}-0.05 \\
\text { ref }\end{array}$ & 0.09 & $-0.23-0.14$ & 0.24 & NS \\
\hline Drinking patterns (AUDIT) & $\begin{array}{r}\text { Excessive drinking } \\
\text { Moderate drinking } \\
\text { Abstinence }\end{array}$ & $\begin{array}{c}-0.36 \\
-0.41 \\
\text { ref }\end{array}$ & $\begin{array}{l}0.15 \\
0.14\end{array}$ & $\begin{array}{l}-0.66--0.07 \\
-0.68--0.15\end{array}$ & $\begin{array}{l}5.75 \\
9.25\end{array}$ & $\begin{array}{l}0.016 \\
0.002\end{array}$ \\
\hline Substance abuse (CRAFTT) & $\begin{array}{l}\text { Yes } \\
\text { No }\end{array}$ & $\begin{array}{c}0.14 \\
\text { ref }\end{array}$ & 0.15 & $-0.14-0.43$ & 0.96 & NS \\
\hline Disordered eating symptoms & $\begin{array}{l}\text { Yes } \\
\text { No }\end{array}$ & $\begin{array}{r}0.47 \\
\text { ref }\end{array}$ & 0.13 & $0.21-0.73$ & 12.2 & $<0.001$ \\
\hline \multirow[t]{2}{*}{ Components of Eating (TFEQ) } & $\begin{array}{l}\text { Cognitive Restrain } \\
\text { Uncontrolled Eating }\end{array}$ & $\begin{array}{l}0.01 \\
0.02\end{array}$ & $\begin{array}{l}0.01 \\
0.01\end{array}$ & $\begin{array}{l}-0.02-0.03 \\
0.00-0.04\end{array}$ & $\begin{array}{l}0.19 \\
5.19\end{array}$ & $\begin{array}{c}\mathrm{NS} \\
0.023\end{array}$ \\
\hline & Emotional eating & 0.10 & 0.02 & $0.06-0.14$ & 24.8 & $<0.001$ \\
\hline
\end{tabular}




\section{References}

Adams, D. R., Meyers, S. A., \& Beidas, R. S. (2016). The relationship between financial strain, perceived stress, psychological symptoms, and academic and social integration in undergraduate students. J Am Coll Health, 64(5), 362-370. doi:10.1080/07448481.2016.1154559

Adams, T., \& Rini, A. (2007). Predicting 1-year change in body mass index among college students. $J$ Am Coll Health, 55(6), 361-365. doi:10.3200/JACH.55.6.361-366

Baecke, J. A., Burema, J., \& Frijters, J. E. (1982). A short questionnaire for the measurement of habitual physical activity in epidemiological studies. Am J Clin Nutr, 36(5), 936-942.

Benjamin, L., \& Wulfert, E. (2005). Dispositional correlates of addictive behaviors in college women: binge eating and heavy drinking. Eat Behav, 6(3), 197-209. doi:10.1016/j.eatbeh.2003.08.001

Bennett, J., Greene, G., \& Schwartz-Barcott, D. (2013). Perceptions of emotional eating behavior. A qualitative study of college students. Appetite, 60(1), 187-192. doi:10.1016/j.appet.2012.09.023

Bittencourt, S. A., Lucena-Santos, P., Moraes, J. F., \& Oliveira Mda, S. (2012). Anxiety and depression symptoms in women with and without binge eating disorder enrolled in weight loss programs. Trends Psychiatry Psychother, 34(2), 87-92.

Bohn, M. J., Babor, T. F., \& Kranzler, H. R. (1995). The Alcohol Use Disorders Identification Test (AUDIT): validation of a screening instrument for use in medical settings. J Stud Alcohol, 56(4), 423-432.

Bongers, P., Jansen, A., Havermans, R., Roefs, A., \& Nederkoorn, C. (2013). Happy eating: the underestimated role of overeating in a positive mood. Appetite, 67, 74-80. doi:10.1016/j.appet.2013.03.017

Boujut, E., \& Bruchon-Schweitzer, M. (2009). A construction and validation of a Freshman Stress Questionnaire: an exploratory study. Psychol Rep, 104(2), 680-692. doi:10.2466/pro.104.2.680-692

Bourdier, L., Orri, M., Carre, A., Gearhardt, A. N., Romo, L., Dantzer, C., \& Berthoz, S. (2018). Are emotionally driven and addictive-like eating behaviors the missing links between psychological distress and greater body weight? Appetite, 120, 536-546. doi:10.1016/j.appet.2017.10.013

Braden, A., Musher-Eizenman, D., Watford, T., \& Emley, E. (2018). Eating when depressed, anxious, bored, or happy: Are emotional eating types associated with unique psychological and physical health correlates? Appetite, 125, 410-417. doi:10.1016/j.appet.2018.02.022

Brook, C. A., \& Willoughby, T. (2016). Social anxiety and alcohol use across the university years: Adaptive and maladaptive groups. Dev Psychol, 52(5), 835-845. doi:10.1037/dev0000110

Brunault, P., Courtois, R., Gearhardt, A. N., Gaillard, P., Journiac, K., Cathelain, S., . . Ballon, N. (2017). Validation of the French Version of the DSM-5 Yale Food Addiction Scale in a Nonclinical Sample. Can J Psychiatry, 62(3), 199-210. doi:10.1177/0706743716673320

de Lauzon, B., Romon, M., Deschamps, V., Lafay, L., Borys, J. M., Karlsson, J., . . Fleurbaix Laventie Ville Sante Study, G. (2004). The Three-Factor Eating Questionnaire-R18 is able to distinguish among different eating patterns in a general population. J Nutr, 134(9), 2372-2380.

De Young, K. P., Zander, M., \& Anderson, D. A. (2014). Beliefs about the emotional consequences of eating and binge eating frequency. Eat Behav, 15(1), 31-36. doi:10.1016/j.eatbeh.2013.10.012

Deasy, C., Coughlan, B., Pironom, J., Jourdan, D., \& McNamara, P. M. (2015). Psychological distress and lifestyle of students: implications for health promotion. Health Promot Int, 30(1), 77-87. doi:10.1093/heapro/dau086 
Decamps, G., Boujut, E., \& Brisset, C. (2012). French college students' sports practice and its relations with stress, coping strategies and academic success. Front Psychol, 3, 104. doi:10.3389/fpsyg.2012.00104

Duclos, M., Dejager, S., Postel-Vinay, N., di Nicola, S., Quere, S., \& Fiquet, B. (2015). Physical activity in patients with type 2 diabetes and hypertension--insights into motivations and barriers from the MOBILE study. Vasc Health Risk Manag, 11, 361-371. doi:10.2147/VHRM.S84832

Evers, C., Adriaanse, M., de Ridder, D. T., \& de Witt Huberts, J. C. (2013). Good mood food. Positive emotion as a neglected trigger for food intake. Appetite, 68, 1-7. doi:10.1016/j.appet.2013.04.007

Forero, C. G., Maydeu-Olivares, A., \& Gallardo-Pujol, D. (2009). Factor Analysis with Ordinal Indicators: A Monte Carlo Study Comparing DWLS and ULS Estimation. Structural Equation Modeling: A Multidisciplinary Journal, 16(4), 625-641. doi:10.1080/10705510903203573

Gache, P., Michaud, P., Landry, U., Accietto, C., Arfaoui, S., Wenger, O., \& Daeppen, J. B. (2005). The Alcohol Use Disorders Identification Test (AUDIT) as a screening tool for excessive drinking in primary care: reliability and validity of a French version. Alcohol Clin Exp Res, 29(11), 20012007.

Garcia Carretero, M. A., Novalbos Ruiz, J. P., Martinez Delgado, J. M., \& O'Ferrall Gonzalez, C. (2016). Validation of the Alcohol Use Disorders Identification Test in university students: AUDIT and AUDIT-C. Adicciones, 28(4), 194-204. doi:10.20882/adicciones.775

Garcia, F. D., Grigioni, S., Chelali, S., Meyrignac, G., Thibaut, F., \& Dechelotte, P. (2010). Validation of the French version of SCOFF questionnaire for screening of eating disorders among adults. World J Biol Psychiatry, 11(7), 888-893. doi:10.3109/15622975.2010.483251

Hamilton, K. R., Ansell, E. B., Reynolds, B., Potenza, M. N., \& Sinha, R. (2013). Self-reported impulsivity, but not behavioral choice or response impulsivity, partially mediates the effect of stress on drinking behavior. Stress, 16(1), 3-15. doi:10.3109/10253890.2012.671397

Jaaskelainen, A., Kaila-Kangas, L., Leino-Arjas, P., Lindbohm, M. L., Nevanpera, N., Remes, J., . . . Laitinen, J. (2015). Psychosocial factors at work and obesity among young finnish adults: a cohort study. J Occup Environ Med, 57(5), 485-492. doi:10.1097/JOM.0000000000000432

Kandiah, J., Yake, M., Jones, J., \& Meyer, M. (2006). Stress Influences appetite and comfort food preferences in college women. Nutrition Research, 26, 118 - 123.

Karila, L., Legleye, S., Beck, F., Corruble, E., Falissard, B., \& Reynaud, M. (2007). [Validation of a questionnaire to screen for harmful use of alcohol and cannabis in the general population: CRAFFT-ADOSPA]. Presse Med, 36(4 Pt 1), 582-590. doi:10.1016/j.Ipm.2007.01.005

Kelly, T. M., Donovan, J. E., Chung, T., Bukstein, O. G., \& Cornelius, J. R. (2009). Brief screens for detecting alcohol use disorder among 18-20 year old young adults in emergency departments: Comparing AUDIT-C, CRAFFT, RAPS4-QF, FAST, RUFT-Cut, and DSM-IV 2-Item Scale. Addict Behav, 34(8), 668-674. doi:10.1016/j.addbeh.2009.03.038

Kloos, A., Weller, R. A., Chan, R., \& Weller, E. B. (2009). Gender differences in adolescent substance abuse. Curr Psychiatry Rep, 11(2), 120-126.

Knight, J. R., Sherritt, L., Shrier, L. A., Harris, S. K., \& Chang, G. (2002). Validity of the CRAFFT substance abuse screening test among adolescent clinic patients. Arch Pediatr Adolesc Med, 156(6), 607-614.

Koenders, P. G., \& van Strien, T. (2011). Emotional eating, rather than lifestyle behavior, drives weight gain in a prospective study in 1562 employees. J Occup Environ Med, 53(11), 12871293. doi:10.1097/JOM.0b013e31823078a2

Kuntsche, E., Knibbe, R., Gmel, G., \& Engels, R. (2005). Why do young people drink? A review of drinking motives. Clin Psychol Rev, 25(7), 841-861. doi:10.1016/j.cpr.2005.06.002

Labouvie, E., \& Bates, M. E. (2002). Reasons for alcohol use in young adulthood: validation of a threedimensional measure. J Stud Alcohol, 63(2), 145-155.

Masheb, R. M., \& Grilo, C. M. (2006). Emotional overeating and its associations with eating disorder psychopathology among overweight patients with binge eating disorder. Int J Eat Disord, 39(2), 141-146. doi:10.1002/eat.20221 
Mikolajczyk, R. T., El Ansari, W., \& Maxwell, A. E. (2009). Food consumption frequency and perceived stress and depressive symptoms among students in three European countries. Nutr J, 8, 31. doi:10.1186/1475-2891-8-31

Moore, C. F., Sabino, V., Koob, G. F., \& Cottone, P. (2017). Neuroscience of Compulsive Eating Behavior. Front Neurosci, 11, 469. doi:10.3389/fnins.2017.00469

Morgan, J. F., Reid, F., \& Lacey, J. H. (2000). The SCOFF questionnaire: a new screening tool for eating disorders. West J Med, 172(3), 164-165.

Oliver, G., \& Wardle, J. (1999). Perceived effects of stress on food choice. Physiol Behav, 66(3), 511515.

Peterson, R. E., Latendresse, S. J., Bartholome, L. T., Warren, C. S., \& Raymond, N. C. (2012). Binge Eating Disorder Mediates Links between Symptoms of Depression, Anxiety, and Caloric Intake in Overweight and Obese Women. J Obes, 2012, 407103. doi:10.1155/2012/407103

Pinaquy, S., Chabrol, H., Simon, C., Louvet, J. P., \& Barbe, P. (2003). Emotional eating, alexithymia, and binge-eating disorder in obese women. Obes Res, 11(2), 195-201. doi:10.1038/oby.2003.31

Richard, J., Palle, C., Guignard, R., Nguyen-Thanh, V., Beck, F., \& Arwidson, P. (2015). La consommation d'alcool en France en 2014. Retrieved from Paris: http://inpes.santepubliquefrance.fr/CFESBases/catalogue/pdf/1632.pdf

Rosenbaum, D. L., \& White, K. S. (2015). The relation of anxiety, depression, and stress to binge eating behavior. J Health Psychol, 20(6), 887-898. doi:10.1177/1359105315580212

Sandstrom, G. M., \& Dunn, E. W. (2014). Social Interactions and Well-Being: The Surprising Power of Weak Ties. Pers Soc Psychol Bull, 40(7), 910-922. doi:10.1177/0146167214529799

Sanlier, N., Baser, F., Mortas, H., Navruz Varli, S., Macit, M. S., \& Tatar, T. (2017). Structural Modeling the Relationship of Food Addiction and Eating Attitudes of Young Adults with Emotional Appetite and Self-Esteem. Ecol Food Nutr, 56(6), 514-529. doi:10.1080/03670244.2017.1388232

Sirohi, S., Van Cleef, A., \& Davis, J. F. (2017a). Binge-like intake of HFD attenuates alcohol intake in rats. Physiol Behav, 178, 187-195. doi:10.1016/j.physbeh.2016.10.006

Sirohi, S., Van Cleef, A., \& Davis, J. F. (2017b). Intermittent access to a nutritionally complete high-fat diet attenuates alcohol drinking in rats. Pharmacol Biochem Behav, 153, 105-115. doi:10.1016/j.pbb.2016.12.009

Tavolacci, M. P., Grigioni, S., Richard, L., Meyrignac, G., Dechelotte, P., \& Ladner, J. (2015). Eating Disorders and Associated Health Risks Among University Students. J Nutr Educ Behav, 47(5), 412-420 e411. doi:10.1016/j.jneb.2015.06.009

Tavolacci, M. P., Ladner, J., Grigioni, S., Richard, L., Villet, H., \& Dechelotte, P. (2013). Prevalence and association of perceived stress, substance use and behavioral addictions: a cross-sectional study among university students in France, 2009-2011. BMC Public Health, 13, 724. doi:10.1186/1471-2458-13-724

1471-2458-13-724 [pii]

Tembo, C., Burns, S., \& Kalembo, F. (2017). The association between levels of alcohol consumption and mental health problems and academic performance among young university students. PLoS One, 12(6), e0178142. doi:10.1371/journal.pone.0178142

Tyson, P., Wilson, K., Crone, D., Brailsford, R., \& Laws, K. (2010). Physical activity and mental health in a student population. J Ment Health, 19(6), 492-499. doi:10.3109/09638230902968308

Val-Laillet, D., Aarts, E., Weber, B., Ferrari, M., Quaresima, V., Stoeckel, L. E., . . Stice, E. (2015). Neuroimaging and neuromodulation approaches to study eating behavior and prevent and treat eating disorders and obesity. Neuroimage Clin, 8, 1-31. doi:10.1016/j.nicl.2015.03.016

Van Strien, T., Schippers, G. M., \& Cox, W. M. (1995). On the relationship between emotional and external eating behavior. Addict Behav, 20(5), 585-594.

Verger, P., Guagliardo, V., Gilbert, F., Rouillon, F., \& Kovess-Masfety, V. (2010). Psychiatric disorders in students in six French universities: 12-month prevalence, comorbidity, impairment and 
help-seeking. Soc Psychiatry Psychiatr Epidemiol, 45(2), 189-199. doi:10.1007/s00127-0090055-z

Wansink, B., Cheney, M. M., \& Chan, N. (2003). Exploring comfort food preferences across age and gender. Physiol Behav, 79(4-5), 739-747.

Zakhem, E., El Hage, R., Peze, T., Hurdiel, R., Zunquin, G., \& Theunynck, D. (2015). [Factors associated with eating disorders in students of the University of Littoral Cote d'Opale]. Rev Epidemiol Sante Publique, 63(4), 259-265. doi:10.1016/j.respe.2015.04.014 